DOI 10.37882/2500-3682.2020.11.16

\title{
ЭССЕ О ЛЮБВИ И ВЕРЕ И О ТОМ, КАК ОНИ СООТНОСЯТСЯ СО ЗРЕЛОСТЬЮ ЛИЧНОСТИ
}

\section{ESSAYS ON LOVE AND FAITH AND HOW THEY RELATE TO PERSONAL MATURITY \\ A. Machukha \\ O. Vasilyeva}

Summary: The article presents the results of a study whose relevance lies in a number of unresolved issues of the phenomenon of personal maturity, which acts as one of the most important indicators of its construct, characterized by the ability to self-disclosure, experience intimacy, which in General can be understood as the ability to love. The analysis of the literature and the form of presenting its results allowed us to reflect the author's understanding of the phenomenology of love, which is presented in many aspects in the works of a number of researchers.

Keywords: personal maturity, love, faith, morality, empathy, selfrestoration, self-development.

\section{Введение}

$\mathrm{B}$ наиболее ёмких, на наш взгляд, работах по изучению феномена личностной зрелости $[3,9,10]$, в качестве одного из наиболее важных показателей ее конструкта, прямо или косвенно, говорится о способности человека к формированию широких и позитивных связей с миром, его способности к самораскрытию, переживанию интимности, что, в целом, при обобщении может быть понято как способность человека любить.

Однако уже предварительный анализ литературы по психологии и философии любви позволяет обратить внимание на ряд особенностей понимания этого явления. Во-первых, публикаций, так или иначе касающихся проблематики любви сравнительно немного; во-вторых, большинство из опубликованных работ как бы «обкатывают» и вновь переосмысливают уже имеющееся ее понимание, и все это не позволяет хоть сколь-либо «закрыть» тему в завершенности ее предмета анализа. И хотя и выдвигаются какие-то идеи, как например, связать любовь с теорией А.А. Ухтомского о центрах возбуждения. [6], и это уже выглядит, на наш взгляд в достаточной степени спекулятивным, т.к. уже сам создатель теории обращал внимание на постоянное наличие какого-либо очага возбуждения в коре мозга (мы мыслим, и уже это означает наличие доминаты) [5]. Иные, пролонгирующие свои идеи в исторический ракурс авторы, предлагают, например, усматривать корни любви мужчины к женщине как попытки компенсировать «дань» женщине

\author{
Мачуха Александр Михайлович \\ Соискатель, Южный Федеральный Университет \\ aleksandrinfo@bk.ru \\ Васильева Ольга Семеновна \\ К.б.н., профессор, Южный Федеральный Университет \\ vos@sfedu.ru
}

Аннотация: В статье представлены результаты исследования актуальность которого заключается в ряде неразрешенных вопросов феномена личностной зрелости, выступающей в качестве одной из наиболее важных показателей ее конструкта, характеризующегося способностью к самораскрытию, переживанию интимности, что в целом может быть понято как способность любить. Анализ литературы и форма предоставления его результатов позволили отразить авторское понимание феноменологии любви, многоаспектно представленное в работах ряда исследователей.

Ключевые слова: зрелость личности, любовь, вера, нравственность, эмпатийность, самостановление, саморазвитие.

за тысячелетнее над нею рабство [2]. Однако здесь хочется заметить, что женщина и в древнем обществе (как например, Древняя Греция и Древний Рим [8] не выполняла роль рабыни, она просто была «иной», контакта с ней и боялись, и считали такой контакт достаточно «нечистым» (и основания здесь во многом достаточно психологические: как дала жизнь (родила), так может и может ее и отнять (vagina dentate), женщина имеет иные возможности фертильности и вступления в сексуальный акт (регулы, факт беременности), чем мужчина и ее естественные физиологические проявления многими культурами нередко считались нечистыми; ей не давали возможности образования уже потому, что общество было специфически мужским, ориентированным на экспансию, и в этой связи женщине в основном отводили детородную функцию, а также можно выделить еще целый ряд причин относиться к женщине как к «иной», но не как к рабыне); у древних семитов отношение к женщине было фактически таким же, как и к мужчине, хотя это так же были два разных (мужских и женских) мира, но именно евреи и почитали женщин, и весьма были позитивно настроены на секс, где, однако, и у них он имел множественные ограничения [4]. Да и в средневековом конкубинате Европы от женщины далеко не всегда требовали сексуального подчинения и не всегда обязывали ее более тяжелой работой, чем других домочадцев.

В то же время анализ литературы позволяет выявить и весьма интересные работы со вполне жизненными, интересными философскими и психологическими наблю- 
дениями, однако мы не ставим целью их обобщать, и, по сути, в этой связи избрали не совсем научный стиль повествования - эссе, в котором попытаемся отразить свое понимание феноменологии любви, избегая, однако, не всегда опирающихся на «философию жизни» так широко цитируемых идей Э. Фромма о «дающей» зрелой любви (как именно всего этого достичь в обыденной жизни среднестатистическому человеку?) и идей В. Франкла о заботе как высшем смысле (и здесь мы придерживаемся того убеждения, что «бог в мелочах, а дьявол в крайностях» (приписывается И.В. Гете), ведь известно, что «дающей заботой» можно испортить любого ребенка, если эта забота неразумна). Другая причина, почему мы прибегли к стилю эссе, кроется в самом феномене любви: то, что мы горячо доказываем сегодня, рассуждая о любви, уже завтра нами воспринимается с некоторым сомнением, а еще позже и вовсе мы готовы отказаться от обсуждения этой темы. Само же слово «любовь» подразумевает под собой так много объектов (от возвышенного до пошлого), что введение этого понятия в дискурс может иметь рамки от поэтичного до анекдотичного, от академического до кухонного (и здесь иногда уместного песенное «о любви не говори, о ней все сказано»), но парадоксальным является профанный язык любви: фраза «я тебя люблю» звучит и как признание, и как открытие, и как всеобъемлющее и всевыражающее смысл дальнейшей жизни, и как приговор.

Однако забегая наперед, мы бы хотели обратить внимание на два постулата, которым мы будем придерживаться.

Во-первых, мы считаем заблуждением считать противоположностью любви ненависть: любовь и ненависть - это полюса одного и того же явления, в пользу которого можно сказать, что все «разведенки» знают, что «половинка», от которой мы отказались, будет чуть ли всю жизнь привлекать наше внимание, как минимум проявлением нашего интереса к ее жизни «без нас». Противоположностью любви, согласно нашей точки зрения, является безразличие, ибо только оно снимает любую эмоциональную пристрастность к человеку, и прежде всего в этом контексте мы понимаем христианскую заповедь любви к ближнему, а именно - не проявлять безразличия, по крайней мере, к тем людям, которые, так или иначе, оказываются вблизи «орбиты нашей жизни». Любовь же очень энергозатратна, и при всем нашем старании, будь мы хоть тысячи раз честны, мы оказываемся не в состоянии «одарить» своей любовью всех на свете (но иметь установку ненасилия даже в мыслях - мы способны).

Второй постулат отражает фактически две, на наш взгляд, формы или вида существующей человеческой любви, имеющей два принципиально разных источника: «любви снизу» и «любви сверху». «Любовь снизу» - это совокупность тех характеристик и проявлений любви, которые в человеке формируются на стыке биологического и социального (а в человеке именно на стыке того и другого). «Любовь сверху» - это любовь, исходящая из духовности, из смыслов, из возвеличения Другого и нахождения ценности и смысла в «ино-» (иное, чем только мое) существования, в трансцендентном, и это сближает любовь к богу и любовь к Человеку в признании за ним Личности и Исключительности.

Попробуем сначала развести эти явления (любовь «снизу» и «сверху»), а потом их объединить, отдавая, по мере своих возможностей, внимание «деталям», и это, на наш взгляд, и сможет позволить нам понять суть и место любви в контексте вопроса зрелости личности.

\section{Теоретический анализ проблемы исследования}

Сегодня уже вряд ли найдется психолог, отрицающий важность идей психоанализа в психологии развития. Стихли также и критические замечания по поводу избыточной биологизации психоанализом человеческой природы, так часто слышимые и со стороны отечественных, да и ряда западных авторов, особенно представителей гуманистической психологии, часто желающих видеть человека как стремящегося только к своим высшим проявлением, и считавшим, что все «эти невротические колебания» лишь признак незрелости, которые должны закончиться с наступлением если не пубертата, то уж юности несомненно (В. Франкл, А. Маслоу и др.).

Напомним, что, согласно психодинамической концепции, ребенок в своем развитии с момента рождения и до 5-6 лет проходит стадии психосексуального развития: оральную, анальную, уретральную, фаллическую (эдипальная фаза) и латентность (6-7 лет). Каждая их фаз имеет специфические проявления, обусловленные сочетанием одновременно биологического созревания организма ребенка, а также психологической спецификой объектных взаимоотношений («объектных» от кляйнианской идеи интроекции частичных объектов: вначале груди, затем, постепенно частичной интроекции психических проявлений ухаживающего объекта), реализуемых, с одной стороны, через субъектность самого ребенка, с другой стороны - через особенности поведения ухаживающего объекта (родителя или лица, выполняющего его функцию). При этом помимо матери ребенок уже достаточно рано начинает формировать свое отдельное отношение и к другим членам своего близкого окружения, особенно отцу, если он в нем присутствует.

Каждая из фаз психосексуального развития имеет свои множественные проявления, причем по мере развитии психоанализа, и, благодаря, начиная от идей его «отца-основателя» 3. Фрейда, и, включая сегодняшних и практикующих, и, по сути, психоаналитиков-философов, все больше и глубже осмысляющих и теорию психоанализа, и вклад в нее психоаналитиков-практиков, 
признаки проявлений каждой фазы развития все более накапливаются, и касаются они и физических проявлений, и психологических, и проявлений, реализуемых в поведении, и на стыке физического и психического, т.е. имеющих соматическую, но психогенную природу.

Так обобщающими признаками орального характера могут выступать поведенческая несамостоятельность, зависимость от отношений и, в принципе, вообще широкий спектр зависимого поведения, в том числе нервные анорексия и булимия, а также желание «уйти от мира» (или его исказить, «приукрасить») посредством химических зависимостей. Некоторые психогенные кожные заболевания и заболевания легочной системы, а также некоторые виды аллергических реакций, астму, иногда связывают с оральной фиксированностью (оральность это еще и контакт тела, ведь в норме мать часто прижимает ребенка к своему телу, обеспечивая ему необходимое тепло и ощущение защиты, а страх может вызывать ощущение нехватки воздуха). Существенная часть заболеваний желудочно-кишечного также может быть психогенной и связанной с нарушениями отношений в период оральности.

Особенностями анального характера еще со времен 3. Фрейда считается стремление к чистоте и порядку, что связывается в общем с тем, что это фаза приучения ребенка к горшку, к навыкам чистоплотности. Однако при этом подразумевается, что ребенок колоссальным образом отличается от взрослого, и самые большие его ценности еще находятся в нем самом; самая большая его ценность это он сам, и он еще не отличает телесное от психического, для него они едины, и его тело в этом ключе его фактически единственная обладаемая им ценность. Но ценностью тогда становятся и производимые телом выделения. Ребенок приходит к выводу, что, сдерживая и выдавая каловые массы в определенное время, он совершает «социально полезную работу». Примерно в русле этой детской логики в анальную фазу развития укладываются и чистоплотность, и бережливость, и агрессивность (ребенка нередко удерживают на горшке с применением определенного усилия). И максимальными в этом русле проявлениями такого характера могут быть жадность, садизм, навязчивое стремление к порядку. Но ведь другим вектором проявлений же анального характера может выступать и неряшливость, и расточительность, и мазохизм («если ты сейчас не покакаешь (или не поешь), я тебе точно врежу (или «брошусь с балкона»). Мое терпение лопнуло!»).

Типичным для анального характера также считают стремление считать буквально все, и вот уже знак как символ приписывают именно анальному характеру. И в этом ключе для верующего человека с таким характером Бог где-то в глубине души предстает неким бухгалтером, подробно фиксирующим и все его добрые дела, и все прегрешения. При этом и самые распространенные ком- пульсивные типы характеров («уходить» в работу, чтобы избавить себя от тревог и страхов, и здесь уже не так важен результат работы, сколько сам ее процесс), и весьма распространенные обсессивные типы характеров (постоянно что-либо обдумывать) относят к анальной фиксированности (логикой обсессивного обдумывания может быть, например, следующее: «как же мне сделать так, чтобы не оказаться наказанным, но при этом получить желаемое?!»).

При этом, как уже было сказано, все новое и новое осмысление вариантов человеческого поведения, производимое различными авторами, выводит в свет новые понимания особенностей проявлений характеров, на которые ранее не обращалось внимание или которое легко соотносились совершенно с другими явлениями. Так В.П. Руднев [7, с.49] совершенно в ином ракурсе, чем это можно представить, рассматривает характер Дона Жуана в аспекте постоянной смены женщин (казалось бы фаллическое самоутверждение, истекающее из эдипальных отношений), считая его характер компульсивным (или обсесивным, что, однако, не делает больших различий для обсессивного и компульсивного характеров). Смена партнерш для Дона Жуана, по В.П. Рудневу, сродни коллекционированию, свойству, столь типичному для обсессивно-компульсивных характеров.

Но если это так, то и сексуальные отношения для каждого типа характеров очень различны, и если для орального типа, не акцентируя особое внимание на поцелуях и характерных типах также именуемого типа контакта, это, прежде всего, объятия и прижатия, то для анального типа характер это и определенная фиксированность (или полное избегание как отрицание) соответствующего коитуса, но и в той или иной мере причинение насилия (себе или партнеру) как минимум в фантазии.

Итак, мы видим, что лишь приблизившись и только прикоснувшись к двум типам характеров, постулируемых психоанализом (оральном и анальном, на деле же их в каждом типе несколько, депрессивный или гипоманиакальный, шизоидный в оральном, и т.д., а в жизни мы всегда имеем дело с сочетанными характерами), мы сталкиваемся с широкой вариативностью их проявлений. И здесь также можно выделить целый ряд особенностей и развития, и воспитания, которые очень трудно обойти. И прежде всего, это сама специфика телесной фиксированности психологического онтогенеза человеческого ребенка (самого длинного и сложного для всех млекопитающих). Так на оральной стадии минимальные биологические требования ребенка в пище, тепле и безопасности, которые по-разному могут обеспечиваться различными вариантами ухода за ним. При этом каждый ребенок имеет свои врожденные особенности, и рожденный младенец с сильной соматической организацией и сильной нервной системой будет обладать большей фрустрационной устойчивостью, а без фрустрации по 
различным поводам не могут обойтись никакие отношения. Другой «подветренной» стороной отношений, но формирующих сильные «ветреные потоки», является мать ребенка, тоже живой человек, имеющий в той или иной мере ограниченный опыт поведения во всех жизненных сферах, и, прежде всего, в уходе, и, вообще, в отношении к ребенку (особенно если это первенец). Получивший ту или иную психологическую травму в оральной фазе своего развития ребенок имеет все шансы получить ее и на последующих фазах, уже потому, что травма вызывает негативное эмоциональное возбуждение, и это уже вариант искажений восприятия мира с одной стороны, и вариант для развития самых разных фрустраций у матери и других воспитывающие его лиц с другой. С другой стороны, вызывающая негативный опыт мать в оральной стадии развития ребенка (по ряду причин: из за своей недостаточной эмоциональной устойчивости, недостаточности опыта и т.д.), это все ma же мать с поведенческими «сбоями», которая будет присутствовать в жизни ребенка и дальше. Из этого вытекает и та особенность ситуации, состоящая в том, что воспитывают ребенка далеко и далеко не идеальные люди, имеющие свои «дефекты» развития (не считая текущих различных «трудностей» жизни), но здесь также есть две особенности для взрослой жизни: во-первых мы все «макаренки», т.е. «не нужно меня учить воспитывать моего ребенка; меня же воспитали мои родители, и я неплохо живу; ну, может, и были какие-то ошибки, но все же со мной все нормально!»; во-вторых, каждый из нас имеет в своем характере невротическое зерно (и хорошо, если это не ядро), но обращение к которому извне вызывает у нас бурную реакцию (негодование и обиду: мы бережем его как зеницу ока, и прежде всего потому, что, не то что, что не хотим его замечать, но потому, что не знаем как исправить ситуацию; иначе говоря, если бы знали, то жили бы по другому). Как следствие, с одной стороны, в семье идет трансляция из поколения в поколение пре- или невротической патологии (иногда и более глубокой), с другой стороны - всегда есть риск формирование новой.

Простой жизненный пример, коих каждый из нас может привести множество. Одним из целого ряда проявлений характера уже не слишком молодой женщины (44 года) является особенность не тушить ночью свет в квартире, где она спит, и, зачастую, не выключать телевизор (причины включенного света и не выключенного телевизора ею всегда рационализируются). Характер женщины достаточно сложный и сочетанный, помимо фобичности и не явной параноидности, здесь также можно выделить некоторую сензитивность, лабильность, но что также немаловажно - ее рентность в отношениях с мужчинами, которых помимо мужа (после развода) было не слишком много, но они были, и лишь последний мужчина задержался более чем на три года (женщина никогда не работала и занималась хозяйством, и, нужно признать, достаточно охотно). Следует отдать должное тому, что эта женщина очень любит своих детей, а их двое. Стар- ший сын два года назад получил диплом бакалавра по технической востребованной специальности, но по профессии работать не стал. Младшая - девочка, которой сейчас 9 лет, и именно ее касаются два замечания, на которых мы бы хотели обратить внимание. Примерно год назад наша героиня (мама) поведала в прочем разговоре весть о том, что ее дочка спит со сформировавшейся семейной парой в одной комнате и так или иначе не единожды была свидетелем постельных сцен с участием мамы, но на обращение соседкой внимания мамы на это обстоятельство наша героиня заметила, что «она еще ничего не понимает». Второй момент, на который хотелось бы обратить внимание, это постоянные окрики мамы с балкона (3-й этаж) в адрес дочери, играющей с детьми: «Кристина, ты где?», «Кристина, ты внизу?», «Кристина, а с кем ты?», «Ты же никуда не ходи!» и т.д. Понятно, что мама очень любит дочь и очень боится ее потерять. Однако уже краткое наблюдение за девочкой показывает, что девочка очень подвижна, эмоционально востребована и сверстниками, и более маленькими детьми, и, в первую очередь, мальчиками, но она уже в разговоре с мамой постоянно перескакивает с тему на тему, и это уже может свидетельствовать о постоянном вытеснении ребенка. Не будучи слишком сензитивной, как ее мать, и не испытывая таких параноидных страхов как она, чем может решить проблему материнского контроля и своей несамостоятельности девочка? Бунтом ранней сексуальности (т.е. началом половой жизни как можно раньше)? Ведь потенциально истерический характер уже сформирован. Это один из многих примеров трансляции патологии отношений через патологию характера в поколениях, и, при этом, мать проявляет исключительную любовь и заботу к своим детям.

Ниже мы представим собственную концепцию понимания двух форм любви, основанную на принятии нами как классической традиции объектных отношений (М. Кляйн и О. Кернберг), так и лакановской идеи Другого, и также на идее Д. Винникотта о промежуточном объекте.

Мы считаем, что можно выделить лишь два вида любви (к ближнему): любовь-обладание (в целом - как вещью) (холдинг) и любовь-расширение (своего Я) (в контексте экстенсивности), всегда подразумевающая Другого как отдельную Личность (и в концепции Ж. Лакана Другого именно следует понимать как Личность, как психическое образование, и никогда как Тело). Агрессию же следует понимать как агрессию, направленную на обладание (удержание), и агрессию, направленную на разрушение. Агрессивное обладание в сексе (женщиной) близко к любви-обладанию, но в любви-обладании все же так или иначе присутствуют признаки личности (в аспектах персоны или индивидуальности) сексуального объекта, и здесь именно отношения, начавшиеся изначально только как сексуальные, могут на какое-то время переходить в разряд влюбленности (очарованно- 
сти) объектом, но и в таких фантазмах присутствует не личность партнера, а его «сома», сопряженная с индивидуальностью-персоной, пока эти отношения не перерастают в действительную влюбленность, если партнер удовлетворяет ожиданиям субъекта сексуальных отношений, и здесь постепенно отношения все более и более «обрастают» расширением (дружба - это расширения Я за счет личности Другого, влюбленность - это гиперрасширение за счет фантазма «объединения» личностей, и, при этом, личность объекта влюбленности приобретает черты позитивной гиперинфляции за счет приписываемых ей положительных черт и ожиданий), либо отношения сходят на нет, т.К. привязанность была сформирована лишь на очаровании его тела, сексуальном голоде субъекта и его ожиданиях и проекциях, и длительность такой очарованности обусловлена в основном способностью субъекта избавляться от своих иллюзий. Агрессивное обладание объектом может чаще всего носить черты садизма; это может быть дичь, подстрелянная на охоте; это выигранная сделка, в которой проигравшая сторона - средство или поверженный оппонент; это вспаханная земля, сделанное дело и т.д., но всегда «добыча» неодушевляется, хотя всегда же здесь присутствует Наблюдатель, даже из числа Жертв, но смысл агрессии-обладания всегда имеет психологическую подоплеку (как минимум - в самоутверждении субъекта). Садизм фашистов подразумевал наблюдателей в других фашистах, в жертвах, а чаще - в лице Смерти: убивая других и наблюдая за их мучениями можно впасть в иллюзию контроля над собственной смертью с целью уменьшения страха смерти.

По своей природе колебания любви-обладания и агрессии-обладания и есть суть профанного человеческого существования, так или иначе себя сублимирующего. Разрушительная агрессия - это и есть то влечение к смерти (переход в Ничто), которые описывают психоаналитики от 3. Фрейда, В. Штекеля, С.Н. Шпильрейн и до настоящего времени. В этом смысле деяния фашистов ближе к агрессии-разрушению, но последнее - это уже фактически «билогический» импульс, практически уходящий из области социального.

И здесь можно цитировать: «С.Н. Шпильрейн писала лишь о том, что «инстинкт сохранения вида по своей сути амбивалентен; поэтому возбуждение положительной составляющей вызывает одновременно возбуждение отрицательной и наоборот» [1, с.47]. Она полностью соглашается со В. Штекелем, который также выводит деструктивные тенденции из сексуальности, но не сексуальные тенденции из деструктивности. Она цитирует его слова о том, что «высшее удовлетворение жизнью часто выражается в желании смерти». Однако и здесь нам представляется, что уничтожающая агрессия лишь в своей крайней патологии представляет собой жажду членения трупов или живого тела (что на наш взгляд показывает власть над живым и над мертвым, т.е. всемогущество), но в большинстве случаев «перевод в ничто» начинает- ся с детского «я тебя убью», что по сути означает «уйди с глаз моих, я не хочу тебя видеть», является средством восстановления (социальной) справедливости (местью) или в случае направления агрессии на себя (самоубийства) - местью себе за неудавшуюся жизнь (Э. Фромм), и такое желание смерти самому себе, т.е. финальную точку депрессии, как это показывает А. Лоуэн, является лишь желанием все начать сначала.

Любовь-обладание в первую очередь и в своей основе предметна, но всегда или практически всегда связана с заботой (уходом): цветы нужно поливать, мясные продукты испортятся, если их забыли положить в холодильник, вещи нужно стирать и гладить и т.д. Но (предмет) неживое достаточно легко забыть, выбросить или уничтожить, если этот предмет не стал для нас символом (т.е. мы его отчасти не «оживили», встроив в систему собственных смыслов, а через них - в структуру своих воспоминаний, связанных с чувственной тканью нашего сознания). Забота и уход (за предметами) также связаны с необходимость оберегать то, что для нас значимо («мило»), т.е. связано с нашими эмоциями и чувствами, и чем эти переживания глубже, тем более дороги для нас эти предметы.

В противовес любви-обладанию выступает любовьрасширение как «раздвигание» границ нашего живого Я с помощью Другого Живого, но это возможно лишь, если мы наделяем Другого свойствами живого (одушевленного) предмета, и это «наделение» начинается с наших эгоцентрических проекций и лишь гораздо позже мы начинаем видеть в другом его индивидуальные характеристики. И это осуществляется благодаря взаимодействию двух механизмов: эмпатии как реализации нашего эмоционального проникновения (первоначально - резонанса) с миром Другого, и образования ментального опыта, в начале как «примеривания» к ситуациям Другого собственных переживаний в аналогичных ситуациях, позже - как совокупности интеллектуально-мыслительного понимания своеобразия индивидуальности Другого, что следует из различных источников познания (обсуждения, разного рода информация о «человеках», собственные наблюдения и выводы, и все это очень часто обрывочно, фрагментарно, мифично, т.е. слабо систематизировано).

Взаимодействие двух механизмов любви - любвиобладания и любви-расширения вкупе с обладаниемагрессией формирует у нас очень широкие возможности для развития личностной патологии.

Однако живыми маркерами любви-обладания и любви-расширения, на наш взгляд, выступают и более глубокие механизмы. Любовь-обладание - это, прежде всего телесный контакт, в то время как знак любви-расширения - ментальность, более область воображаемого. В этой связи мы также хотели бы обратить внимание 
на такие интересные явления, как подарок или желание: под подарком мы также понимаем желание побаловать себя, в том числе не только покупкой, но, например, и отпуском. Вначале возникает установка (когда она имеет сколь возможный шанс реализоваться), вызывающее стойкое возбуждение в коре мозга, все боле и более усиливающееся, которое снять многие уже не могут. Нам представляется, что схожий механизм имеет и желание (в лакановском понимании). Любая вещь после формирования ее ментального образа в качестве желания, после ее приобретения в начале вызывает стойкое желание тактильного контакта с ней, будь это даже автомобиль, а затем некоторой ментальной проработки, и лишь после рециркуляции того и другого интерес к ней постепенно ослабевает и отношение к ней переходит в ряд отношений обыденного, т.е. эта вещь занимает рядоположенное место с другими нашими вещами, но здесь совершается цикл, включающий в себя работу фантазии, включение фантазии в наше реальное (но наша реальность всегда чувственно-эмоциональна) с последующий символизаций этой вещи. Представляется, что примерно также происходит процесс при неврозе, особенно истерическом: фантазирование объекта - «принца», жизнь с ним и получение разочарования, его обесценивание (отрицательная символизация) и поиск нового. Иначе говоря, подарки для нас, даже сделанные самим себе, в том числе и в виде случайной покупки, имеют смысл символов личностного расширения как недостаточности любви-расширения, что также можно понимать и в случае нашего расширения в случае сенсорной депривации, которую, по сути, следует рассматривать как недостаточность социальных контактов, т.е. присутствия Другого, и материальная вещь, произведенная другими людьми (или даже красоты природы) - это символ расширения (весь окружающий нас мир - «человеческий», «антропийный», и даже находясь на необитаемом острове, и имея при этом собаку или иное сколь развитое по интеллекту животное, мы строим свое общение с ним наподобие человеческого, но всегда имеем внутренний «диалогизированный» монолог, подразумевающий под собой если не обезличенного физически, но конкретизированного в своей ментальности Другого).

В ключе любви-обладания оральная фаза - это решенность или нерешенность прежде всего именно этой проблемы (наполненность или недостаточность обладанием объектом, и, затем, собой). Далее нерешенность вопроса обладания все более переходит в область фантазий, решая или недостаточно решая вопросы расширения, но и обладании есть отдельные моменты, эмоционально отражающие это обладание. Это, как минимум, амбивалентность или однонаправленость импульса (любви и агрессии), а также смешанность переживаний.

При этом со всей очевидностью можно говорить, что чем сильнее внешние или внутренние ограничения, особенно если субъект не может проявлять собственную активность, тем легче будут возникать фантазии (т.е. чем меньше «обладание», тем более можно ожидать «расширение»). На наш взгляд «сочетанную» работу механизма «обладание-расширение» хорошо отражает поговорка «с милым рай в шалаше»: пока длится влюбленность с максимальным расширением личностей друг друга и полным обладанием друг другом, не требуется ни подарков, как не требуется и других людей.

Любовь-обладание, или, точнее, «отношения обладания» («принадлежности») чрезвычайно распространенные явления, прежде всего, в социальных микрогруппах, и к ним могут быть отнесены почти все ролевые взаимоотношения, и родительско-детские, и супружеско-ролевые: они предполагают предписанные нормы социального поведения - «ты (или я) выполняешь(ю) одни определенные функции, а я (или ты) - другие», и это подразумевает вознаграждение (хотя бы в функциях обмена, но в основном - материального). Обладаниеагрессия всегда предполагает использование, что всегда связано с неравнозначностью платы сторон.

Любовь-расширение (своего Я или Я Другого) изначально предполагает отношение к Другому как к Личности (хотя бы в ее потенции).

В контексте отношений «любовь-обладание» и «любовь-расширение» нами предполагается видимость развития и патологий личности - неврозов и психопатий.

Д. Винникотт делает намек на условия формирования здоровой и нездоровой (в будущем) личности: если либидо и агрессия сплетаются воедино, личность Вырастает здоровой, если пути реализации либидо и агрессии не совпадают - «жди» личностной патологи. Еще одно важное замечание Д. Винникотта о промежуточном объекте: (будущие) невротики надолго на нем фиксируются, в то время как (будущие) психопаты и относительно «здоровые» личности проходят этот этап отношений несколько менее замеченным.

По этому вопросу мы бы хотели донести следующие соображения.

Д. Винникотт вводит понятие «достаточно хорошей матери», которое понимается нами не просто в качестве своевременно удовлетворяющей биологические потребности ребенка и создающей ему условия «оптимальной фрустрации», но и обязательно эмпатийной, в целом своевременно «улавливающий» помимо условий для оптимальной фрустрации возможность его соскальзывания в реальную фрустрацию и не допускающей ее глубокого переживания. Чрезмерно заботливая мать инфантилизирует ребенка и своим предвосхищающим удовлетворением потребности провоцирует условия для формирования у ребенка некоего присутствия «идеального бога» как магического удовлетворителя 
всех чаяний ребенка. Этим закрепляется вынесенное идеальное Я ребенка в форме существующего Другого, через обладание которым с последующим лакановским запросом к Другому в любой речи как запросу о любви, а в первые месяцы жизни - в манипулировании ребенком матерью как объектом его желания (можно бросать игрушку, и мать ее будет всегда подавать; можно капризничать и ждать, когда мать будет перебирать все аспекты удовлетворения невыясненных детских запросов и т.д.), и здесь образуется зыбкая грань, когда манипулирование ребенка матерью приведет к инфляции его только зарождающегося Я, т.е. к идеализации самого ребенка и частичному обесцениванию матери, но, тем не менее, к усилению чувства всемогущества ребенка, либо к частичному обесцениванию себя и идеализации матери, особенно если удовлетворение детских запросов парциально и не всегда детерминировано содержанием самого этого запроса (например, у ребенка пучит живот, а его поят водой или баюкают).

Особое место занимают детские страхи, часто обусловленные непониманием матерью его истинных запросов, но особое место в детских страхах имеет страх смерти, что чаще всего, с нашей точки зрения, проявимо у болезненных и депрессивных детей, «зараженных» (чаще послеродовой) депрессией матери, и именно эти дети испытывают страхи, часто именуемые в психоанализе страхом поглощения («вагина дентата»).

Ребенок, реализующий в будущем паттерны достаточно зрелой личности, в своих контактах с матерью помимо любви-обладания уже имеет опыт и любви-расширения, т.е. мать относится к нему уже в достаточной мере эмпатийно, подразумевая в нем как минимум индивидуальность и ориентируя себя видеть в нем и дальше отдельную самостоятельную личность, вероятнее всего обладающую отличительными от всех других людей уникальными характеристиками. Именно эмпатийность матери и ее индивидуальность в отношении к ребенку позволяют ему минимализировать переживание им фрустрации по поводу ее (матери) временной потери (удаления), чему способствует оставляемый матерью ребенку промежуточный объект, и здесь он оказывается именно таким, каким его описывает Д. Винникотт одновременно принадлежащим ребенку и не принадлежащим ему, принадлежащим и внешнему, и внутреннему миру ребенку (его ощущениям) (а как показывает в частности В.Н. Руднев, а также ряд других философов,- нет смысла разделять наше восприятие мира на внешнее и внутреннее, т.к. по общему счету оно все внутреннее), одновременно живым и неживым. Ребенок не боится оставаться наедине с этими мирами, т.к. они все для него «устойчиво живые».

«Будущий невротик» более воспринимает промежуточный объект как живой, и этот внешний мир, к кото- рому принадлежит промежуточный объект, для него более живой, чем он сам, и этот ребенок испытывает постоянную нужду во внешних «живых» объектах, потому что уже почти априорно у него существует внутренняя опустошенность как следствие его самообесценивания. Отсюда постоянный запрос о Другом как более живом объекте у невротика. Отсюда и постоянная необходимость в «промежуточных объектах», столь свойственная невротикам и столь характерная для них привязанность к отдельным вещам (и событиям) как знакам их памяти.

Для «будущего психопата» привычны только отношения обладания: его могли задаривать игрушками, но это всегда откуп от неумения искренне проявить эмпатию, т.е. любовь-расширение. Для них промежуточный объект всегда «мертвый», это только вещь, какой в своей основе является, и он сам, и ухаживающий за ним объект. Специфично и отношение уже «рождающихся» бодерлинов к промежуточному объекту в более позднем детском возрасте - агрессия. Как итог, одни психопаты могут проявлять себя крайне аскетично («зачем другие объекты, если они «мертвые» и не несут в себе тепла»), и этим же может быть отчасти объяснено и современное потребительство: всякая новая купленная вещь подразумевает в себе социальную ситуацию ее использования, в основном обслуживающую нарциссизм или ментальный образ приписываемой субъектом иллюзорной роли, но эту вещь легко «убить» - забыть о ней временно или навсегда, подарить или отдать другому, вообще уничтожить; продукты питания мы просто уничтожаем, съедая, но во всех случаях с вещами мы также реализуем и ряд других психологических механизмов, однако показательно то, что до конца XIX в., т.е. до эры технической революции, когда для успешности произведения массовых продаж продукции производства начала активно использоваться мода, одежду носили до тех пор, пока она окончательно не становилась ветхой, и здесь со всей очевидностью объективно было понимание одежды, с одной стороны, как продолжения своего тела, с другой - как «живого» продукта индивидуального производства, в который ее производитель «вложит душу».

И еще несколько замечаний. Для многих из нас переживание счастья сводится к неравной схеме сложения и получения: получать больше, чем вложено. Жизнь устроена так, что мы не только находим, но и теряем: близких, здоровье, жизнь. В своей ориентированности «иметь», т.е. обладать мы ориентированы в будущее, но этим мы фактически ориентированы материально. Лишь те, кто имел серьезные потери, в серьез начинают оценивать жизнь сегодня, почти телом ощущая, что Жизнь во всех ее проявлениях (в витальности простого проживания, и проживания рядом с нами любимых нами людей и всех живых существ, сотворенного и сущего) дадены единожды и эту даденность можно ощутить лишь в текущем переживании. Будущего нет, потому что оно не определено 
и может в любой момент рухнуть вне нашей воли. Прошлого тем более нет, потому что оно миновало, его нельзя вернуть и его невозможно исправить. Синдромальное проявление нашей зависти к нашему же неумению жить и здесь, и сейчас - это идеалистичное представление о боге, не имеющем тело и сущем вне времени, т.е., что явно, всегда во здесь-и-сейчас. Так может нам проще учиться именно жизни в здесь-и-теперь, и это и оформит нашу память не энграммами, а дорогими нам воспоминаниями, продлит нашу жизнь в будущее, потому что она прекрасна и подлинна, и не страшно, что мы смертны? И в этом ракурсе жизни «сейчас» мы не будем так стремиться «пристроить» своих детей, потому что будем уверены в том, что и они честны и нравственны, как и мы сами, а иные пусть сами отвечают за собственные поступки если не перед Богом, то хотя бы перед совестью?

Но жизнь оказывается гораздо более сложной, и в этой связи и любовь, и зрелость личности, и ее нравственность, и ее чистота имеют и временные (в смысле принадлежности к определенной исторической эпохе и конкретным событиям в ней), и вполне конкретные для собственного выбора особенности измерения, а в общей своей основе для конкретного человека - особенности экзистенциального выбора.

\section{Выво $\Delta ы$}

Как вывод: на наш взгляд именно зрелость личности создает условия для зрелой любви, но зрелость личности могут обеспечивать условия зрелой любви в первичной семье, но и здесь вероятностны сбои в силу ряда причин (уже из-за недостаточности знаний и интуиции у родителей), однако зрелость личности как процесс ориентированного (выбранного) самой личностью самостановления и саморазвития в условиях нерешенности проблем развития - это процесс во многом проб и ошибок, и тогда зрелая любовь такого человека - это тоже процесс проб и ошибок, но здесь могут иметь применение определенные рекомендации: терпимость к ошибкам другого, желание их исправить с нежеланием ему травмы (но без душевной боли это почти невозможно), поддержка и вера в его желание (и полная уверенность в этом для себя) быть рядом. Есть и еще ряд важных условий: понимание единственности и неповторимости имеющихся отношений, верности данному слову. Так, Иван, Семенов сын, герой фильма «Монах и бес», на слова «Уходит от нас!», сказанные в контексте невыполнимости задания об очистке запущенного колодца, ответил: «колодец же пойдет за мной». Таким образом, невыполненная взятая на себя обязанность будет нас преследовать (а это честность долга перед собой), и ряд других, по сути, определяемых категорией «нравственность».

\section{ЛИТЕРАТУРА}

1. Вагин Ю.Р. Теория деструктивного влечения Сабины Шпильрейн. // Суцидология. 2012. №1. С.43-49.

2. Весельева К.В., Юрченко Е.О. Феномен любви в историческом контексте. // Материалы Международной молодежной научной конференции. Ответственный редактор Горохов А.А. 2013 Курск: ЗАО «Университетская книга». 2013. С.272-275.

3. Дерманова И.Б., Манукян В.Р. Личностная зрелость: к определению психологического содержания. // Вестник Санкт-Петербургского университета. Серия 12: психология, социология, педагогика. 2010. №4. С.68-73.

4. Люкимсон П., Котлярский М. Евреи и секс. Аудиокнига. [Электронный ресурс] URL: https://knigiaudio.org/ (дата обращения 27.01.2019)

5. Мальчева С.П. Учение о доминанте А.А. Ухтомского: значение для современной науки. // Научно-техническое и экономическое сотрудничество стран АТР в XXI веке. Хабаровск: Изд-во ДГУПС. 2017. Т.1. С.335-341.

6. Панкратов Н.Н. Смысл любви и настоящая любовь. // Приоритетные научные направления: от теории к практике. Новосибирск: 000 «Центр развития научного сотрудничества». 2016. №33. С.149-167.

7. Руднев В.П. Характеры и расстройства личности. Патография и метапсихология. М.: Независимая фирма «Класс». 2002. 272 с.

8. Сейдгазов М., Чугунова Т., Русаков В. Фаллос как член общества. Аудиокнига. [Электронный источник] URL: https://knigi-audio.com/ (дата обращения 05.06.2019)

9. Скворцова Л.Л. Индивидуально-типологические особенности имплицитных концепций личностной зрелости. // Вестник Могилевского государственного университета им. А.А. Кулешова. Серия С: психолого-педагогические науки: педагогика, психология, методика. Могилев (Беларусь). Изд-во: МГУ им. А.А. Кулешова. 2020. №1(55). С.76-83.

10. Скворцова Л.Л. Сравнительный анализ имплицитных концепций личностной зрелости. // Зборнік навуковых прац акадэміі паслядыпломнай адукацыі. Минск: Государственное учреждение «Академия последипломного образования». 2016. №14. С.380-395. 